\title{
Editorial
}

\section{Publishing ahead of print}

\author{
C. J. Burgoyne \\ University of Cambridge
}

There is a feeling today that if it can't be measured, it doesn't have any value. Scientific journals cannot escape this rule, and the old idea of what constituted a quality journal (that it is held in high regard by its authors and its readers) is no longer sufficient for the bureaucrats.

The quality of an academic's research, or the outcome of a research contract, is assessed against the quality of the journals where the results are published. This in turn has led to attempts to measure the quality of the journal, and the use of 'impact factor' has become pervasive. This tries to measure how much influence papers published in the journal have on the outside world, but it does so in a very limited way. It considers how frequently papers in that journal are cited elsewhere, by counting the average number of times that each paper is cited in the two years after publication.

Civil engineering journals on the whole do not do well by this measure. Few have impact factors $>1$, which implies that on average each paper is only cited once in the next two years, and many, including Magazine of Concrete Research, hover around 0.5. By comparison, medical journals have much higher impact factors, but the work they report is frequently out of date very quickly. Another statistic that is calculated for journals but seldom quoted is the 'cited half-life'; $50 \%$ of the total citations to papers in that journal occur within the cited half-life, the rest later. For medical journals this is a few years, while for $M C R$ and many other civil engineering journals it is $>10$ years. Because engineering changes more slowly, the work goes on being useful. Other alternative measures, more appropriate to engineering or other disciplines have also been proposed, ${ }^{1}$ but the impact factor rules; it smacks of immediacy and importance in a way that politicians and accountants can understand.

One of the reasons that our impact factor is so low is the time it takes to get a paper into publication. If you are going to write something about a paper that has appeared in $M C R$ in such a way that it has an effect on the impact factor, you have to do the work, write the paper, get it through the review process and into print within two years. That is a tall order but it is something that the Editorial Advisory Board and publisher can do something about. Once a paper has been submitted to the journal, reviewed, revised, re-reviewed and accepted, it has to join a queue to find a place in print, and we have recently been receiving a record number of submissions which means that this time has increased significantly. There is good work sitting there that no one can read. So $M C R$ is the first of the Thomas Telford journals to publish on-line versions of the paper 'Ahead of Print'.

Ahead of Print papers will be made available as soon as they have been accepted for publication, typeset and checked. The papers will be identical to the version that will eventually appear in print, the only difference being the absence of page numbers. Crucially, the print version will remain the 'version of record', so the twoyear measure will begin from the time this version is published. Ahead of Print papers for $M C R$ can be found by following the 'Ahead of Print' link on the MCR page (www.concrete-research.com).

Every paper carries a unique digital object identifier or DOI (see http://www.doi.org/). The DOI scheme 
assigns a unique reference to each piece of work. They are used to provide current information, including where the work (or information about it) can be found on the internet. Information about a digital object may change over time, including where to find it, but its DOI name remains the same. Papers in the Ahead of Print queue have the same DOI as the paper that eventually appears in the journal, and authors can make this available to those who wish to refer to their work, either as a web link, or as a published number which can be resolved by going to http://dx.doi.org/.

Taken together, we believe that speeding-up the review process, which is the responsibility of the Editorial Advisory Board, and publishing Ahead of Print with
DOI reference numbers, should improve the quality of the service supplied to the concrete research community worldwide and should keep $M C R$ at the forefront of the journals in this field.

\section{Reference}

1. Adams J. How Good is the UK Research Base? UK Higher Education Policy Institute, Oxford, 2006. See www.hepi.ac.uk/ pubdetail.asp $? \mathrm{ID}=213 \& \mathrm{DOC}=$ Reports $\quad$ (last accessed March 2008).

Discussion contributions on this paper should reach the editor by 1 November 2008 